\title{
The Integration of Museum Resources into the Development of Art Courses
}

\author{
Han Shushu \\ General Graduate School, Joongbu University, Chung Nam, Republic of Korea
}

Email address:

635102117@qq.com

To cite this article:

Han Shushu. The Integration of Museum Resources into the Development of Art Courses. Education Journal. Vol. 9, No. 4, 2020 , pp. 116-126. doi: $10.11648 /$ j.edu. 20200904.15

Received: July 16, 2020; Accepted: August 14, 2020; Published: August 25, 2020

\begin{abstract}
Art education is a gradual process. The cultivation of aesthetic ability cannot be completed within a short period of time, especially that of art creativity. In art teaching, a question worthy of discussion and research is how to cultivate the art creativity of students correctly. By analyzing museum resources and art education in China, this paper aims to effectively analyze, interpret and re-create museum collections, so as to cultivate students' ability to appreciate artworks, improve their interest in art, and develop their ability to create art. In line with the characteristics of the research subject, this research mainly utilizes the literature review method, comparative analysis method, and case study of the investigation method to study the development of art courses for students before entering junior middle schools. According to the survey, the integration between museum resources and art courses has remarkable educational significance. Around the world, many countries have key projects for the construction of art courses in museums. In order to promote the innovation of art education in China, this paper explores the prototype of figurines of a comedic face playing an instrument (喜乐俑) collected by the museums, develops art courses with the integration of this prototype. The final part of the article presents the result of the research, demonstrating a module course and concluding how art teachers can utilize museum resources to develop art educational courses, and discusses some problems of Chinese art education and puts forward some solutions.
\end{abstract}

Keywords: Art Education, Museum Resources, Art Courses

\section{Introduction}

China has been in the primary stage of socialism for a long time and has attached great importance to the development of industry, agriculture, and manufacturing. The teaching system in schools focuses on the construction and development of the subjects of Chinese, mathematics, science, and culture, resulting in a long-term lack of attention to art education courses. With the development of the times, people's requirements for aesthetics have increased. They not only care about the use value of the objects but also attach increasing importance to their design and appearance value. The current situation of design and development in China shows that there are many imitations and the situation of original design and development is not ideal. The root cause of this situation is that the development of China's art education lags behind. Like any kind of education, art education also requires a solid foundation.

In China, primary schools, junior high schools, and senior high schools use nationally unified art textbooks. Although the textbooks are rich in content and cover a wide range of knowledge, the guidance on how to deliver art courses is dull and outdated, not combined with current social culture and contemporary art. However, currently many art training institutions outside schools provide some courses related to museums, but only a small number of students have attended these courses. In the early stage of growth, when children have not fully developed their language ability, they can express their feelings through painting, which is the unique attribute of painting courses. Regarding the art education in kindergartens, art courses are taught in a mechanical way, in which students follow their teacher to draw brushstrokes one at a time. There is no complete art teaching system. Students have no correct understanding of art, let alone the accumulation of aesthetic experience and the thoughts about art creation. Due to the neglect of art curriculum in China's education, many industries in China, though achieving technical development, lack the sense of design, practicality, and innovation. After the 20th century, with the influence of Western culture to some 
extent, China has achieved rapid development in economy and greatly improved Chinese people's living conditions. In better material conditions, people have more time to pursue spiritual enjoyment, spending their spare time on leisure and entertainment. More and more people begin to attach importance to Chinese art education.

Art courses in kindergartens are very important, which will affect students' art learning in primary schools, middle schools and high schools. Art learning is a gradual process. If students are not interested in art creation during the basic teaching period when they are young children, they are likely to abandon art courses in the later period of art learning. In fact, this exerts a negative influence on the development of students' various abilities, and thus the study of art courses is very important for students when they are young children.

Research finds that some first-grade students in primary schools do not know how to paint and show no interest in art in art classes owing to the imperfect arrangement of art teaching curriculum and the lack of cultivation of children's abilities of exploration, creativity, and imagination. This is the reason why I wrote this paper.

\section{Analysis of Museum Resources}

\subsection{Definition and Significance of Museum}

The word "museum" derives from the Greek word "Mouseion", which means "the place for worshiping Muses (the nine goddesses in charge of scholarship and art in the Greek mythology) and research" [1]. Currently, in the world, the most common definition of a museum is a non-profit and permanently open institution for research, appreciation, education which also collects and preserves the material evidence of the environment for the society [2]. According to this definition, museums have educational characteristics. Their educational function lies in that as the second classroom of national education, they undertake the task of providing lifelong education for all citizens after they graduate from schools [3].

In recent years, China has invested a lot in cultural construction. The main purpose of museum construction is to exert its function of education. Museums often hold educational activities, the most common of which are exhibitions. Because museums mainly exhibit historical relics, which cannot be touched or experienced, and the introduction of cultural relics tend to be superficial and simple, it is difficult for students to learn about and understand deeply their value. Secondly, most museums in China do not exhibit their collections in ways particularly designed for students. As a result, students only observe the collections from the surface but have no feelings or understanding.

The resources of museum collections help to study the development of art courses from the perspective of cultural creativity. In school art courses, there are few courses of cultural creativity. Works of art show the combination of culture and creativity and convey rich meanings as cultural products. The main direction to develop art courses is to integrate the analysis of the cultural history of museum collections into the creativity of art courses.

In a broad sense, culture refers to the sum of material wealth and spiritual wealth created in the historical practice of human society. In a narrow sense, it refers to the ideology of the society, as well as the corresponding institutions and organizations. Culture is a kind of historical phenomenon. Every society has its own culture and develops with the improvement of social material production. As an ideology, culture reflects the politics and economy of a certain society and also exerts a great influence on the politics and economy of a certain society [4].

In 2001 in the "Cultural and Creative Green Book", Prime Minister of the United Kingdom Tony Blair emphasized that the British government should support all children, teenagers, artists, and creative workers in the next 10 years so that they can be free from the restrictions of the extremely bureaucratic system in the past and develop their creative potential and talent freely; the government should focus on education and develop different strategies in different stages of the cultivation of creative talents; it should help students in primary and secondary schools understand what is cultural creativity and inspire their interest [5].

\subsection{A Case Study on the Utilization of Museum Resources All over the World}

At present, all countries in the world have developed the cultural industry by taking cultural resources as prototypes. With creativity, the Louvre in France uses two of the most famous cultural figures Mona Lisa and Broken Arm Venus as cultural prototypes, which are printed on bags and glasses cases. The museum directly copies and prints the cultural resources [6].

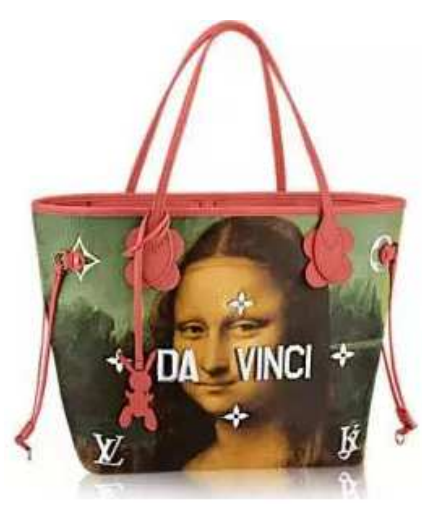

Figure 1. Mona Lisa bag.

Monna Lisa Glasses case
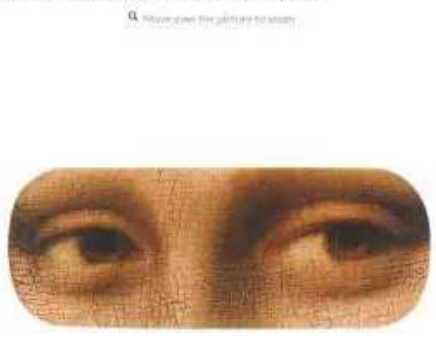

Figure 2. Mona Lisa glasses case. 
The Centre National d'art et de Culture Georges Pompidou Centre in France exhibits post-modernist works and sells products developed based on cultural prototypes. It uses Piet Cornelies Mondrian "Red, Blue, and Yellow Compositions" as cultural prototypes to create commodities composed of the three primary colors. The elements of three primary colors are extracted as cultural prototypes to innovate the design of daily necessities.

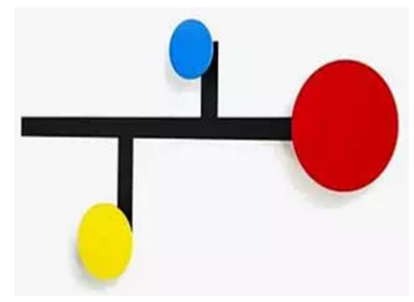

Figure 3. Mondrian's hanger in the three primary colors.

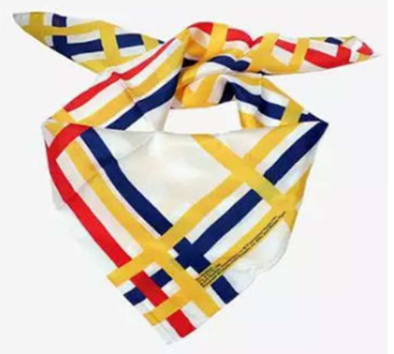

Figure 4. Mondrian's scarf in the three primary colors.

The British Museum of the United Kingdom makes flexible use of cultural resources to design its products in an interesting way. It combines the elements of cultural resources and British local dolls. It produces dolls of the "little yellow duck" which show the cultural characteristics of different countries. Specifically, it makes use of Egyptian and ancient Roman cultural resources in exhibitions to develop dolls of the "little yellow duck" with Egyptian and ancient Roman features [7].

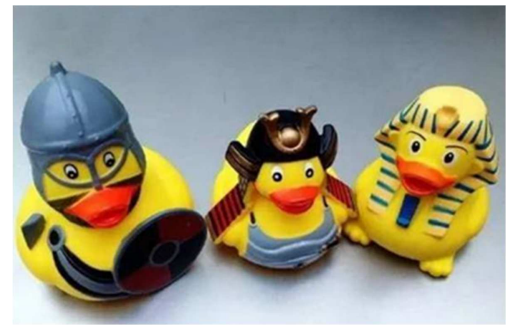

Figure 5. The yellow duck doll.

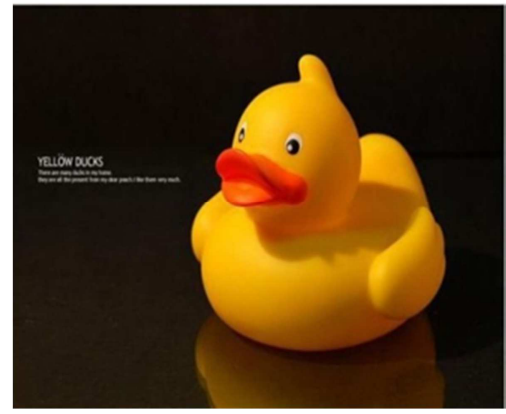

Figure 6. Prototype of the yellow duck.

\subsubsection{Examples of The Development of Chinese Museums}

In recent years, China has also developed museum collection resources based on cultural prototypes, integrating national cultural elements. The development of entity prototypes can be integrated with cultural resources of folk characteristics, such as cultural elements, patterns, and the spirit of cultural inheritance. The prototypes of the artworks are redeveloped in combination with the products [8].

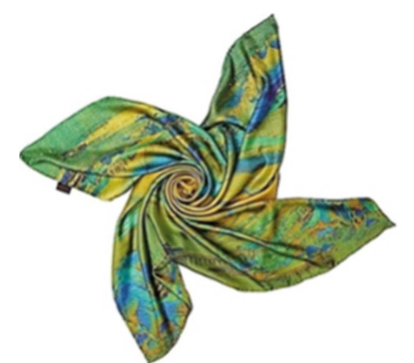

Figure 7. Silk scarf, a souvenir based on A Thousand Li of Rivers and Mountains" in the Palace Museum.

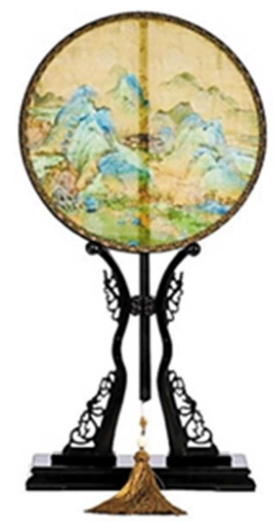

Figure 8. Circular fan a souvenir based on" "A Thousand Li of Rivers and Mountains" in the Palace Museum.

\subsubsection{Take the "A Figurines of a Comedic face Playing an Instrument" as an Example to Conduct a Study}

A figurines of a comedic face playing an instrument (喜乐 俑, a type of pottery figurines in ancient China) is taken as the research subject. The pottery figurines are generally made of clay and used as burial objects. They are representatives and replacements of the living people so that the people are not buried alive. They are the cultural inheritance of the sacrificial system in the Shang and Zhou dynasties and cultural phenomenon generated under the system of mass burial. "They are figures to be buried and serve as the tools for their masters to enjoy themselves. The emergence of pottery figurines actually symbolizes the progress of ancient society [9]. With the development of society, figurines that dances or plays an instrument (乐舞俑) became one of the classic types of pottery figurines. The master enjoyed songs and dances and was indulged in luxury before death. Thus, he wanted to bring all kinds of pleasures with him into the underworld when he died. Igurines that dances or plays an instrument (乐舞俑) accompanied their master to spend the lonely night in the tomb. The important status of figurines that dances or plays an 
instrument (乐舞俑) cannot be ignored. Therefore, the ancient creators made a good combination of form and content when designing figurines that dances or plays an instrument (乐舞 俑). In addition to the primitive and majestic features, they paid attention to freehand brushwork, presentation of concepts, and exaggerated imagination, successfully creating such great pieces of artwork that are displayed in front of people nowadays [10].

A figurines of a comedic face playing an instrument (喜乐 俑) in the Eastern Han dynasty in ancient China showed the harmonious and happy social reality of that period. The simple, healthy, and optimistic appearance of figurines of a comedic face playing an instrument (喜乐俑) vividly depicts the pleasant atmosphere of social life. The simple and cheerful facial expression of the figurines offered a vivid presentation of the emotional states of the people at that time and can also arouse resonance of the audience nowadays. figurines of a comedic face playing an instrument (喜乐俑) of the Eastern Han dynasty shows that ordinary people had an enthusiastic attitude towards life though in an age of political and economic oppression. Museums take figurines of a comedic face playing an instrument (喜乐俑) as a cultural prototype, restore with digital technology the optimism and positiveness shown by the figurines, which people nowadays also yearn for. It is easy for the audience to accept both the image of and emotion conveyed by the figurines, which is in line with the requirements of industrial development.

There are various kinds of figurines of a comedic face playing an instrument (喜乐俑), including figurines that look like people singing and dancing (俳优俑), figurines that look like people playing musical instrument similar to the zither (抚琴俑), figurines that look like people rapping (说唱俑), and figurines that look like playing the drum and rapping (击 鼓说唱俑). Figurines of a comedic face playing an instrument (喜乐俑), presents the images of folk artists performing. Their images are vivid and lively, and their shape is exaggerated and interesting. Figurines of a comedic face playing an instrument (喜乐俑) is a precious kind of tangible cultural heritage in China that gives people joyful feelings. In the Han dynasty, rap performance was very popular among people. Figurines that look like people rapping (说唱俑) catered to the psychological needs of people at that time and showed the leisure and happy image of people after hard work. Figurines that look like people rapping (说唱俑) is small in size and convenient for decoration and circulation.

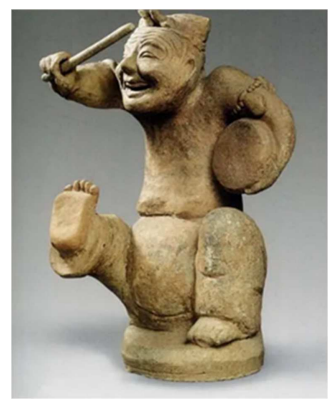

Figure 9. Positive of figurines of a comedic face playing an instrument (喜乐 俑)

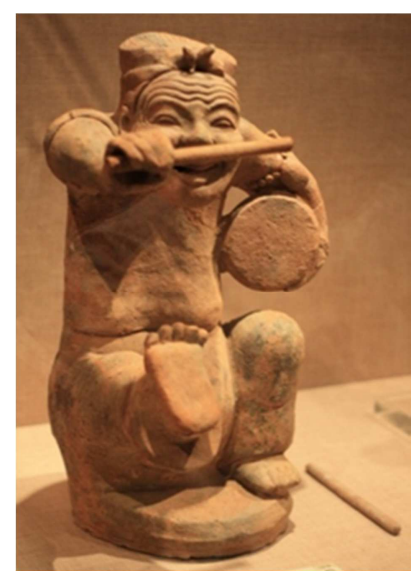

Figure 10. Profile of figurines of a comedic face playing an instrument (喜乐 俑).

The representative work of figurines of a comedic face playing an instrument (喜乐俑) is figurines that look like playing the drum and rapping (击鼓说唱俑), known as the "best figurine of the Han dynasty". It is an excellent clay sculpture with strong folk styles and local characteristics. It is a national first-class cultural relic and is currently collected by the National Museum of China. This figurine represents the highest achievements of folk art in the Han dynasty and has been written into history textbooks. This figurine is $55 \mathrm{~cm}$ high. It wears a kerchief on its head and has wrinkles on its forehead. It has a naked upper body with its arms decorated with strings of beads. It wears trousers and is barefoot. It holds the drum with its left hand and the drumstick in his right hand. It presents a dynamic image of a man performing. From this image, the audience can feel the enthusiasm, optimism, vitality, and sense of humor of the artists at that time [11].

Figurines that look like people rapping (说唱俑) is a piece of artwork that presents the folk performances of the Han dynasty. With the development of multimedia information, in modern society, the Internet, videos, and pictures are used as methods for entertainment and information dissemination. There are very few live performances of the model presented by figurines that look like people rapping (说唱俑). But in China, folk artist performances are part of the history of Chinese performances and are loved by the public. The image of figurines that look like people rapping (说唱俑) is simple and true, which is welcomed by the public. The dynamics, clothing, and musical instruments that it presents have unique morphological characteristics, which show the diversity and realism of Chinese sculpture art.

The cultural value of figurines of a comedic face playing an instrument (喜乐俑) in the Han dynasty is similar to the historical and cultural values pursued by the citizens of modern society in China. In today's society, there is a trend to revive the style of the Han dynasty. Many young Chinese wear hanfu, traditional Chinese clothing of the Han Dynasty, on a fixed day, and many parents have their children wear traditional Han clothing to cultivate their understanding of Chinese culture. The culture of the Han dynasty has been gradually pursued by young people, which is forming a trend. Just as Japanese wear kimonos and Koreans wear hanbok, Chinese wear Chinese clothing of the Han Dynasty. People 
nowadays are also familiar with, recognize, and accept the Han culture. figurines of a comedic face playing an instrument (喜乐俑) is a real existence that belongs to the Han culture, which meets the aesthetic requirements of people in modern society.

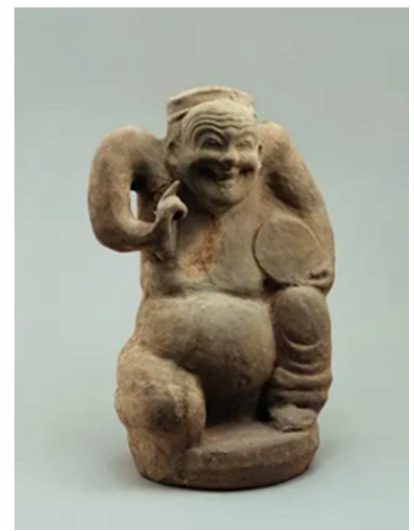

Figure 11. Figurines that look like people singing and dancing (俳优俑)

At present, some collections of Xi Le Yong can be used for the development of souvenirs or products in museums. 1. Figurines that look like people singing and dancing (俳优俑) is a work of stone carving, collected by the Three Gorges Museum in Chongqing, China. It was unearthed from the No. 2 Han dynasty tombs in Ancient sites (羊子山) Mountain in Chengdu in 1954. It is $51.6 \mathrm{~cm}$ high. It has a naked upper body and shrugs its shoulders. It holds the drum on the left side of its waist and its right-hand points at its mouth (the mallet originally in its right hand has fallen).

2. A pottery figurine of the Eastern Han dynasty (东汉俑), collected by the Chengdu Museum, was unearthed in 2006 from the Han dynasty tombs in Lijialiangzi Village, Zhaozhen District, Jintang County. It is $60 \mathrm{~cm}$ high and made of sand and gray pottery. It is hollow, and its all parts are connected after molded. Its upper body is long, and its lower body is short. It wears a flat scarf and has three wrinkles on its forehead. It squints, has a small and high nose, opens its mouth and sticks out its tongue, with neat teeth, a round face, and a happy smile. Its upper body is naked, its shoulders shrug, its breasts sag, and its belly is round. Its left hand holds the drum, its right arm is half-curved, and its right hand holds a drumstick (lost). Its trousers slip down its underbelly. It sits on a round drum. Its left foot curls on the drum and its right foot stretches forward. The towels and drums are painted with vermilion.

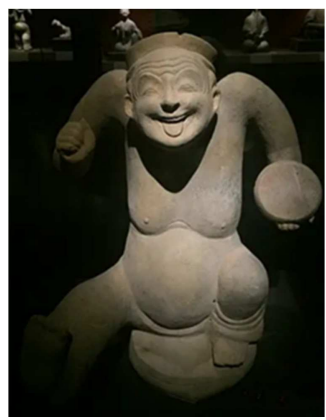

Figure 12. Dong Han Yong.

\subsubsection{Research on the Development Method of "Figurines of a Comedic Face Playing an Instrument"}

The museums analyze the collection of the pottery figurines that look like people rapping (说唱俑) and create artworks based on the analysis. They first draw the figurine in detail. Then they draw the outline of the figurine and design corresponding cartoon image. Thirdly they design different combinations of colors inspired by Pop Art. Fourthly, they integrate the image of the figurine with the elements of music, prints, and the patterns of blue and white porcelain. Fifthly, they print the well-designed image of the figurine on different products such as cups and mobile phone cases.

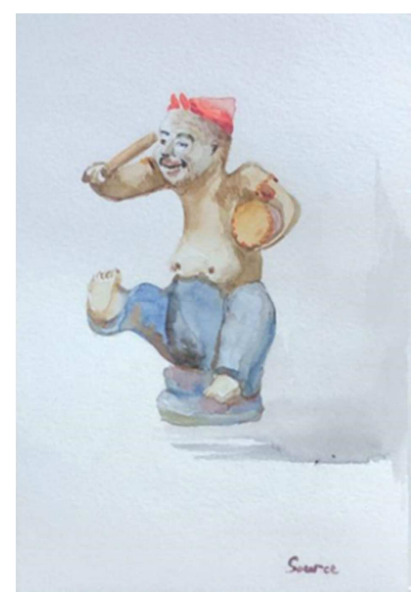

Figure 13. Prototype of the figurine.

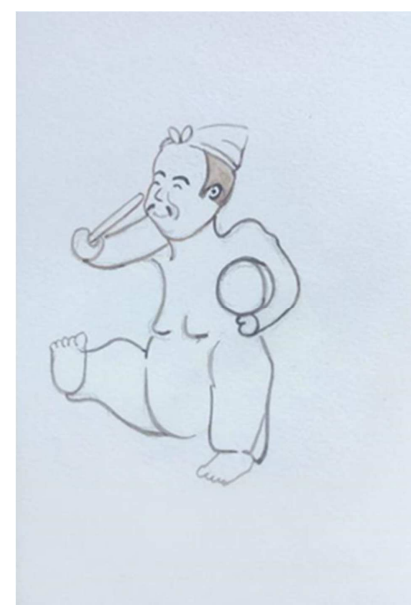

Figure 14. Outline of the figurine.

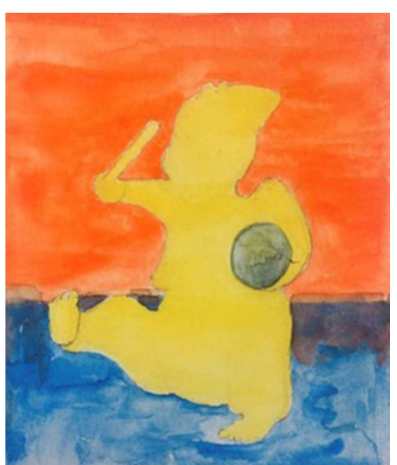

Figure 15. Complementary Color evolvement. 


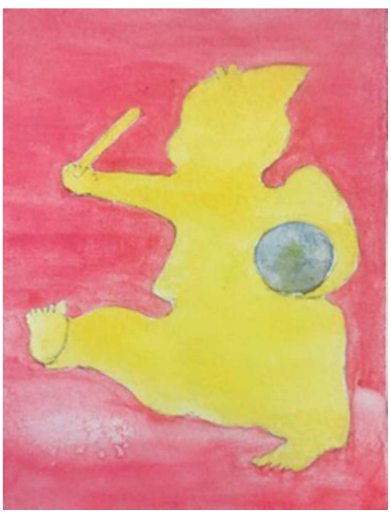

Figure 16. Pink Color evolvement.

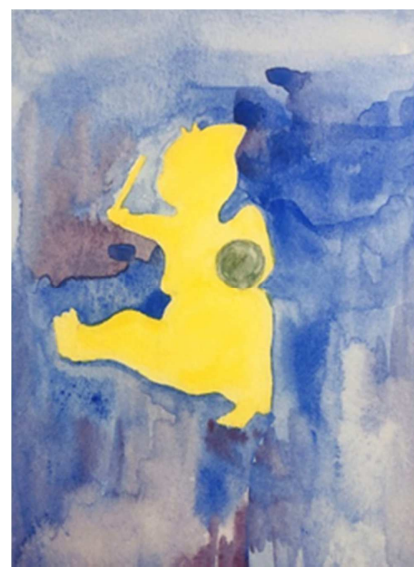

Figure 17. Blue Color evolvement.

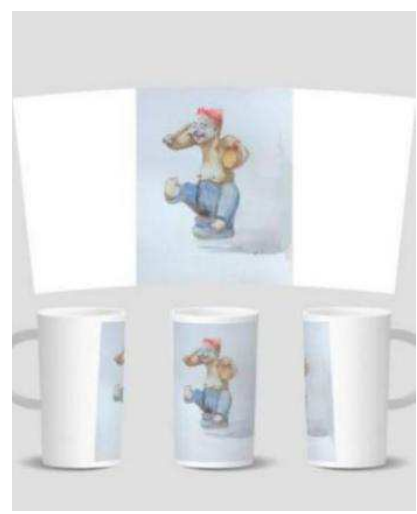

Figure 18. Designs of cups (1).

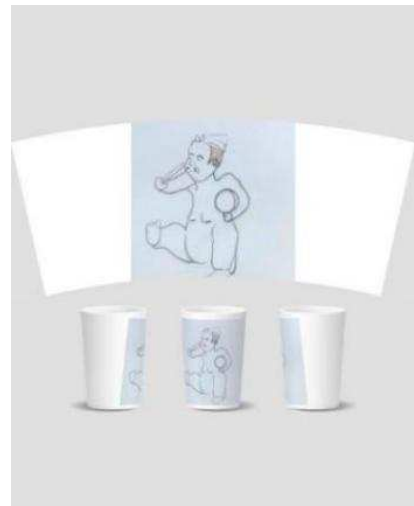

Figure 19. Designs of cups (2).

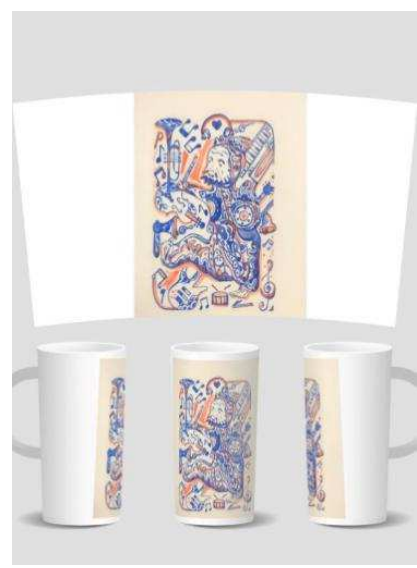

Figure 20. Designs of prints cups.

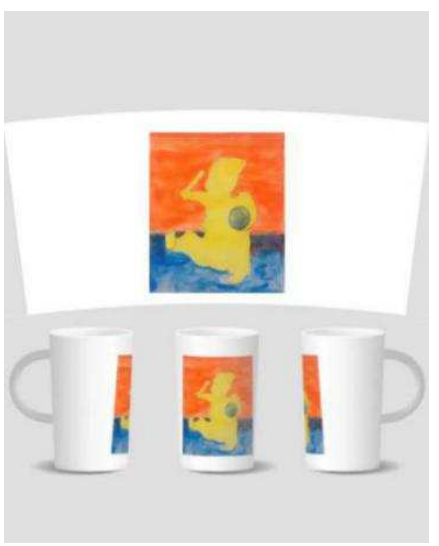

Figure 21. Designs of complementary cups.

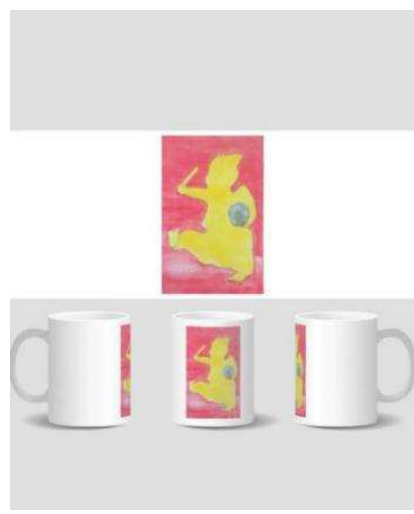

Figure 22. Designs of pink cups.

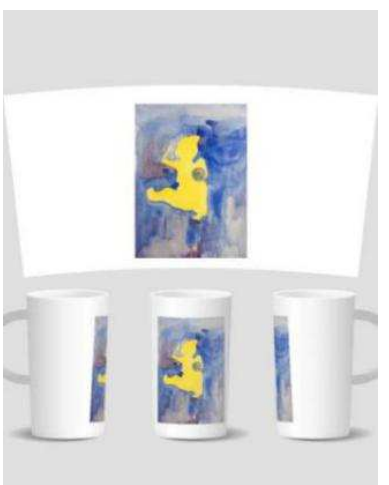

Figure 23. Designs of bule cups. 


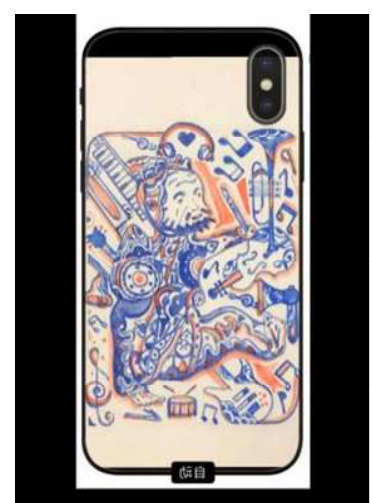

Figure 24. Designs of prints mobile phone cases.

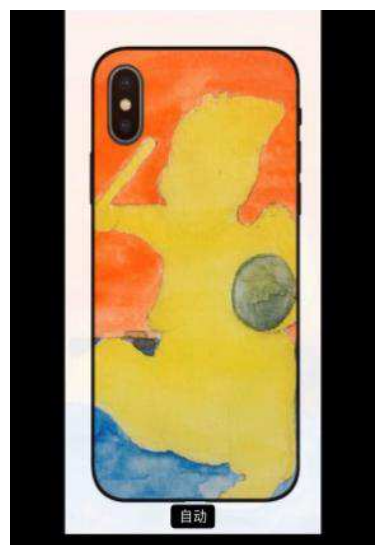

Figure 25. Designs of complementary mobile phone cases.

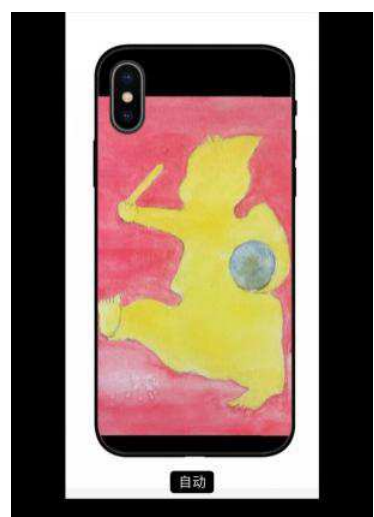

Figure 26. Designs of pink mobile phone cases.

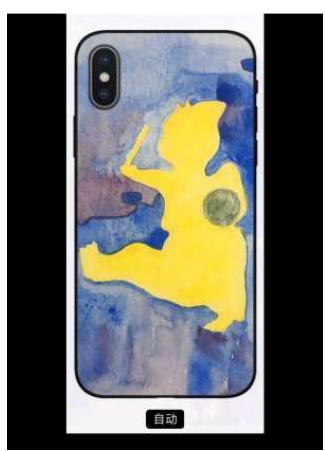

Figure 27. Designs of bule mobile phone cases.

\section{Research on the Method of Curriculum Development Process}

The design of art courses in schools can take the museum collection resources of the pottery figurines that look like people rapping (说唱俑) as the development subject. Figurines that look like people rapping (说唱俑) is a clay sculpture. The art course for third grade in primary schools is named "Time Travel". It can be applied to any art course about human figurines. This course includes four periods. In the first period, the teacher takes students to observe the figurines in museums, patiently explains the history of the figurines and the meaning of their dynamic expressions and asks students to share their feelings about the figurines. In the second and third periods, the teacher prints the image of the figurines, and asks students to select a picture that they like and cut the whole image of the figure with scissors. Then under the guidance of the teacher, students imagine the living environment of the figurines, paste the figurine they have cut down on a paper, and carry out creative painting about the environment. Students can also use clay to present the environment. In this course, museum collections are used as a fixed prototype for art creation, based on which students imagine and draw the environment. With the changes in time and space, the same image of figurines conveys different feelings and meanings.

Before developing this course, I compared the contents of the art textbooks for fifth-grade primary school students in China and South Korea, especially the contents about museum collection resources. The following is the scanned images of the textbooks [12].

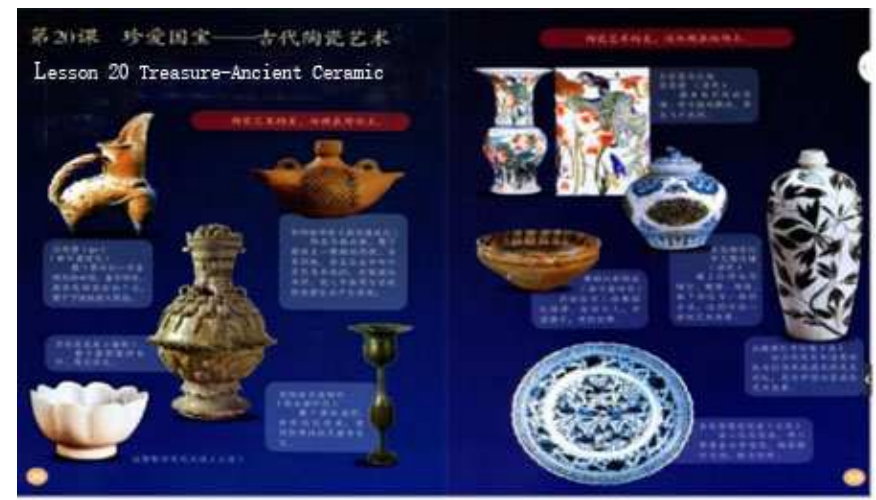

Figure 28. Chinese art textbook for fifth-grade primary school (volume 1) lesson 20. 


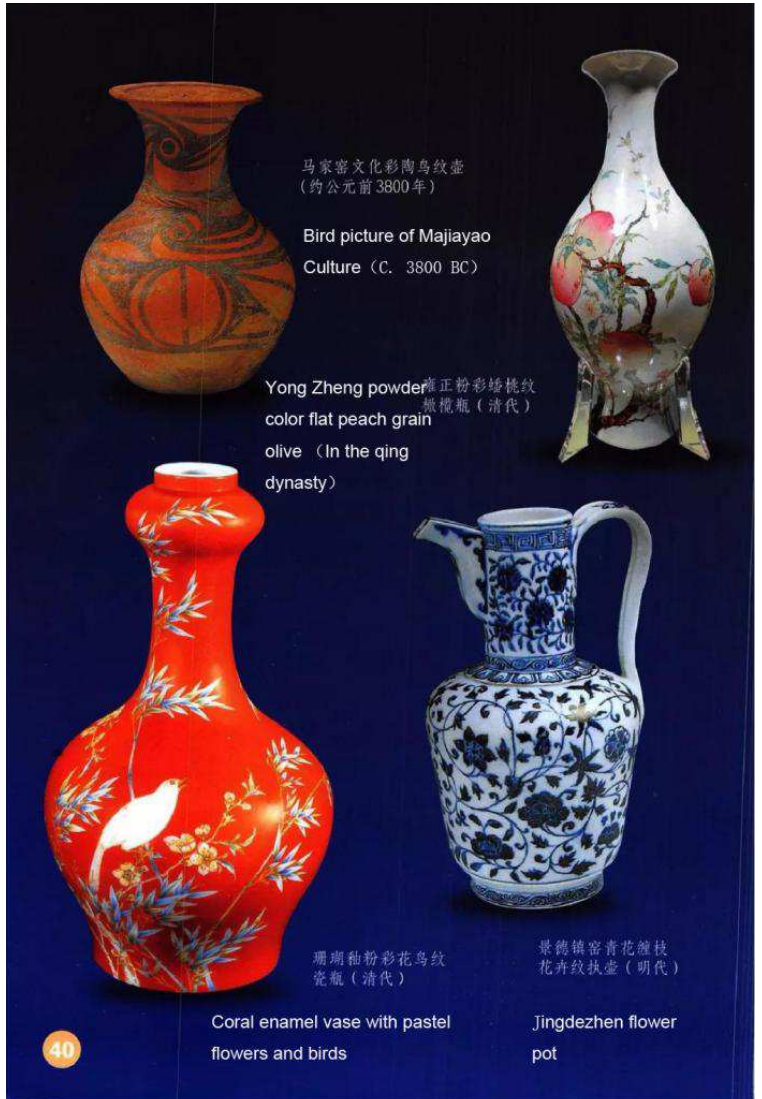

Figure 29. Chinese art textbook for fifth-grade primary school (volume 1), People's Education Publishing House.

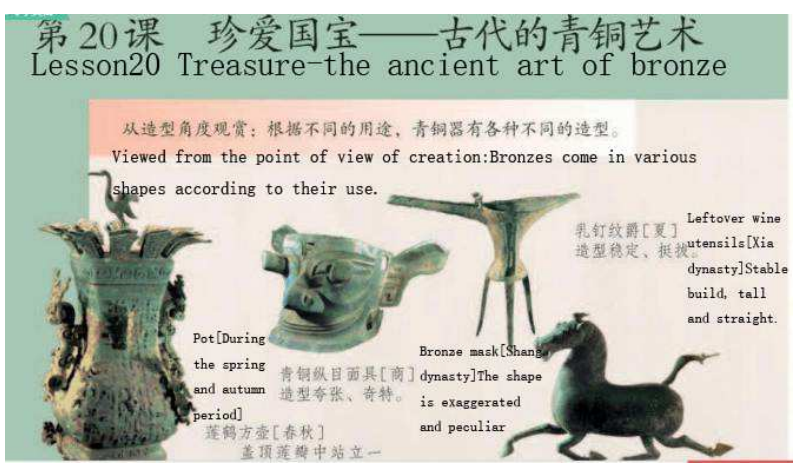

Figure 30. Chinese art textbook for fifth-grade primary school (volume 2) lesson 20.

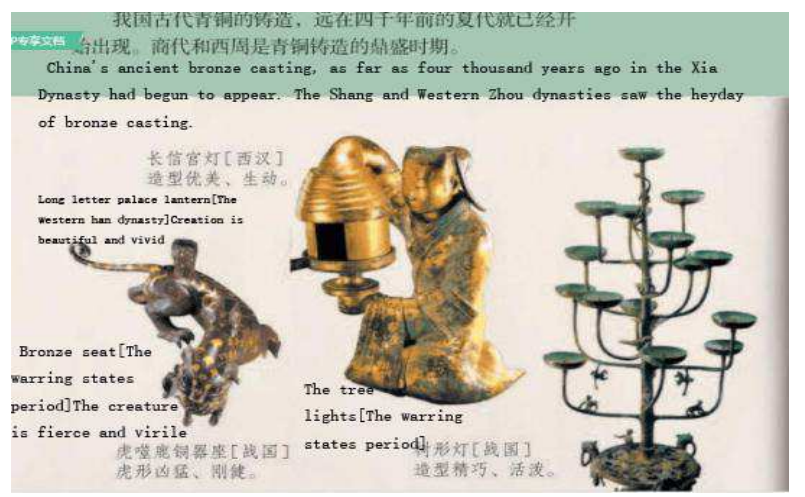

Figure 31. Chinese art textbook for fifth-grade primary school (volume 2) lesson 20 content.

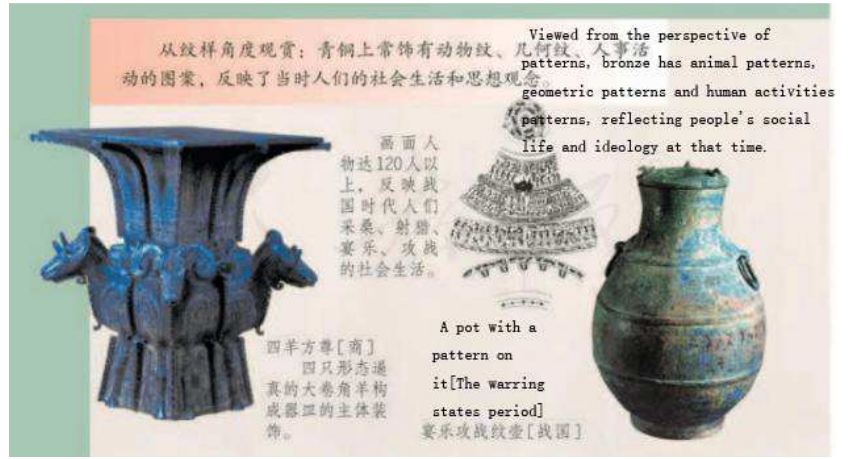

Figure 32. Chinese art textbook for fifth-grade primary school (volume 2) lesson 20 content (1).

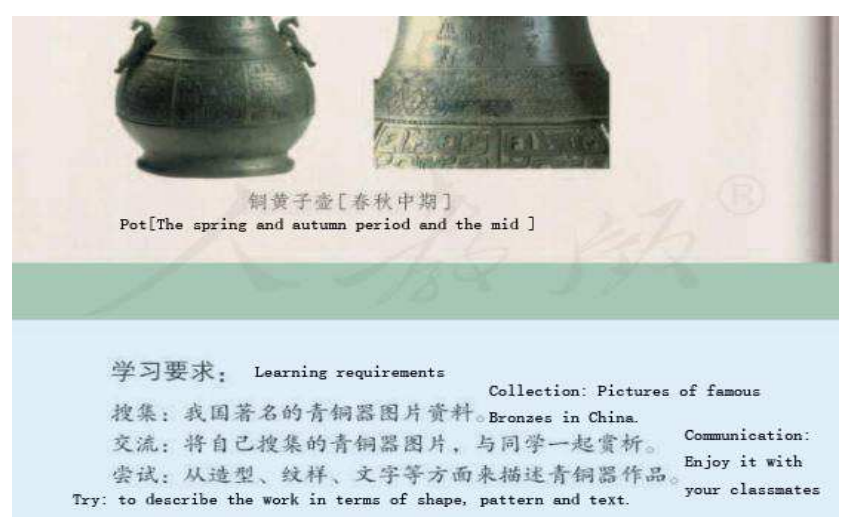

Figure 33. Chinese art textbook for fifth-grade primary school (volume 2), People's Education Publishing House.

Both Chinese and Korean art textbooks mention the collection resources of museums. Chinese art textbooks put this content in the last lesson based on which teachers can carry out an appreciation class. According to the learning requirements on the books, students should collect the pictures of famous bronzes and admire them with classmates. They also need to describe the bronzes from the aspects of creativity, patterns, and words. In Korean textbooks, the lesson is called "let's take an art journey"[13], which requires students to search for artworks in living space. The textbooks introduce Korean museums, including the artworks, the exhibitions in art gallery, and the websites of museums. Students are supposed to develop different feelings about art. They are required to imitate the works in the museums that they like and create their own works with different materials. In my opinion, the content in Korean art textbooks accords more with the significance of art learning. By appreciating artworks, students can develop feelings and be inspired to make some creation. In this way, students can carefully observe the details of the works, deeply remember the works, and uses their imagination about historical artworks to create new products with cultural significance. This course also includes outdoor activities. The teacher can take students to museums for field teaching activities, which is worth learning. 


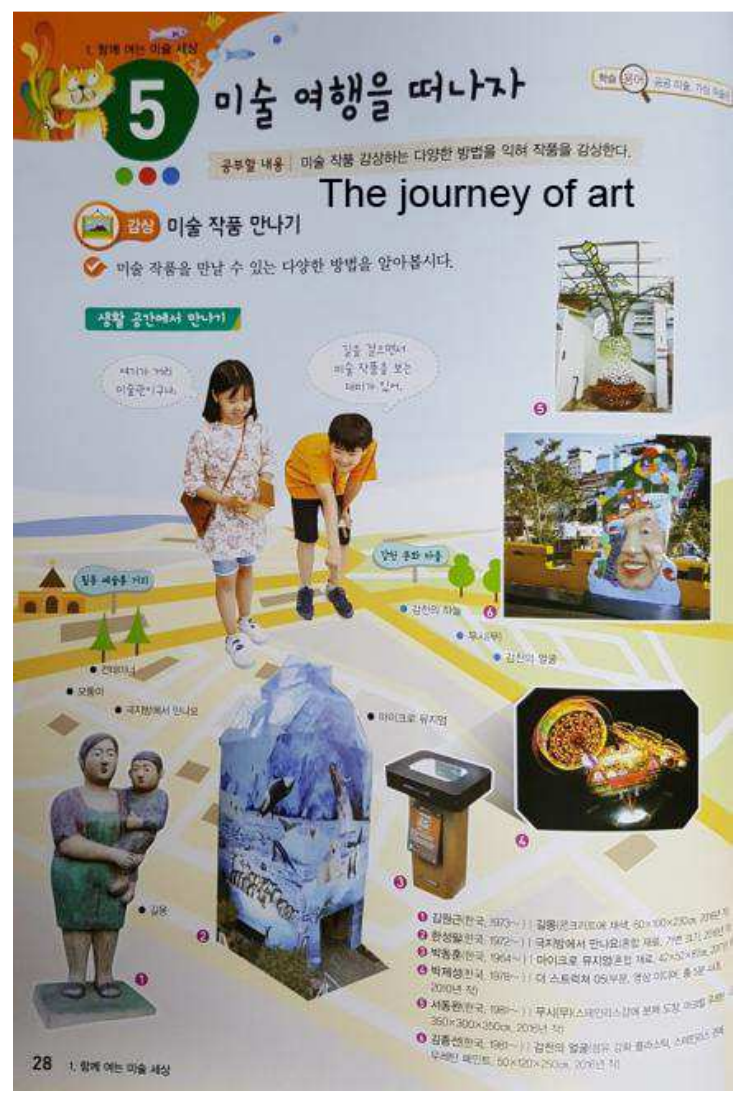

Figure 34. Korean art textbook for fifth-grade primary school students (volume 1) lesson 5.

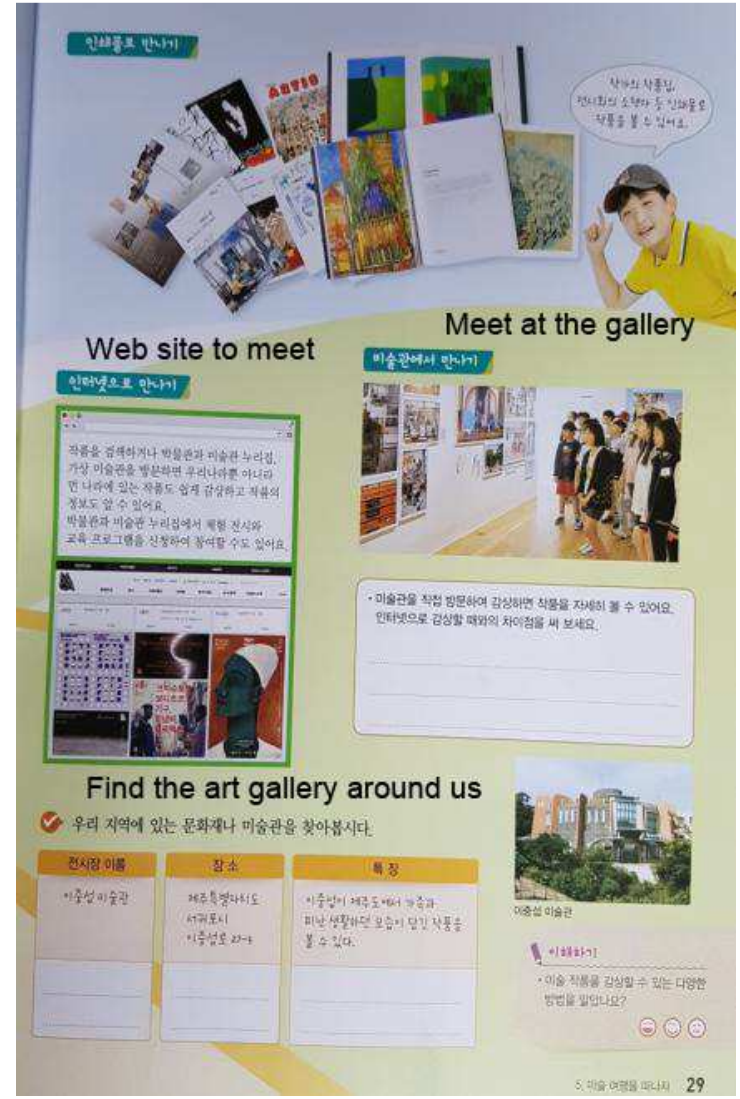

Figure 35. Korean art textbook for fifth-grade primary school students (volume 1) page 29

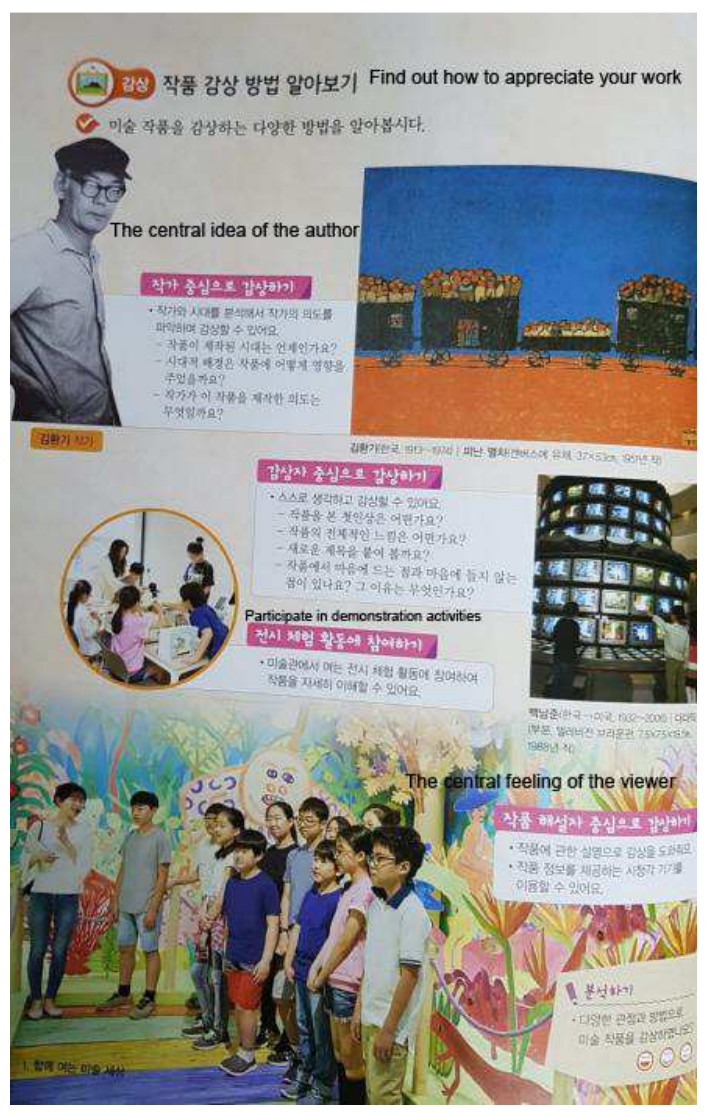

Figure 36. Korean art textbook for fifth-grade primary school students (volume 1) page 30

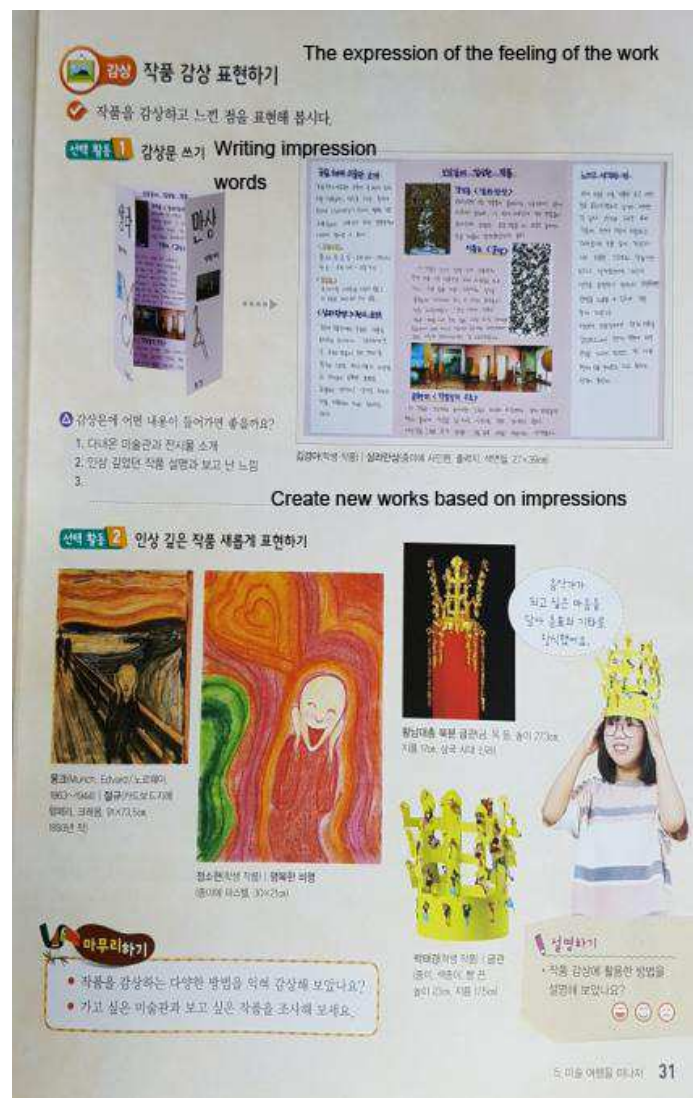

Figure 37. Korean art textbook for fifth-grade primary school students (volume 1) page 31. 


\section{Discuss and Raise Difficulties}

The main research purpose of this paper is to improve the teaching content of art courses in China. After analyzing the use of museum collections in art textbooks, this paper puts forward several solutions to the problems of China's art education. Here are a few points worth discussing: The first one is innovative education, which changes the rigid teaching method in traditional education, gives students more emotional and tactile experience, and allows students to create works with their own feelings. The works created in this way are meaningful and valuable, and the talents and merits of each student are more easily found. What is the educational significance and value of such works? The second one is to cultivate students' initiative. In traditional teaching mode, teachers occupy the leading role in classes. Students tend to lose interest in the course in a passive learning state. To cultivate students' initiative means to motivate students to play the leading role in classes. When students actively engage in the interactive process of teaching and learning, they have an emotional experience with the content, actively think about the creating process of artworks, and acquire a better understanding. However, the key point of this education mode is how to assist the students to become leaders [14]. The third one is to raise questions in classes. Students are sometimes distracted in classes. It often happens that there is no answer after the teacher asks questions, which shows that students do not have feelings or in-depth understanding of the teaching content. To solve this situation, teachers can not only carry out discussions during classes, but also how to mobilize the enthusiasm of students' participation in the classroom. To sum up, art education plays a significant part in the cultivation of students' aesthetic senses and artistic understanding. Teachers need to guide students to express their feelings after they have learned about or admired artworks. Therefore, the design of art courses can be developed from these three aspects.

\section{Conclusions and Recommendations}

In summary, it can be concluded that in the present stage, there is a way of cooperation between art education and museum resource development in China. With the common goal of education, the integration between them is valuable and meaningful [15]. This paper conducts an in-depth analysis of museum collection resources and designs art courses based on artworks originally used only for appreciation, offering new insight into art education and providing some reference. Through these ideas and models, more interesting and innovative art courses can be developed based on museum resources. If in the future, art courses can be integrated with museum resources, it must bring about a breakthrough in art educational courses. Art courses combined with practice will definitely bring different feelings and social experiences to students. For schools and art teachers, they can make use of museum resources to develop the second classroom and practical courses. Teachers can also expand and improve their knowledge.
The article also puts forward some suggestions. Currently, Chinese museums are not proactive in supporting schools. The country does not have good policies to support them and should attach importance to develop the cooperation between museums and schools in terms of education. The educational models of foreign museums can be drawn on. For example, museums can carry out classes to provide short-term training for teachers and short-term thematic practical courses for students. In addition, teachers have insufficient knowledge about museums. Without professional knowledge, it is difficult for teachers to develop interesting courses. It is suggested to provide training for teachers to strengthen the team of teachers.

\section{References}

[1] Wang, Hongjun. Fundamentals of Chinese Museology [M]. Shanghai Ancient Books Publishing House, 2001.

[2] Liu, Wanzhen. Educational Concepts and Practicality of Art Museums [M]. Nantian Book Bureau, 2002.

[3] Zhao, Fangfang. Research on Art Education Cooperation between Museums and Schools [D]. Yunnan Normal University, 2015.

[4] He, Xin et al. Chinese and Foreign Cultural Knowledge Dictionary. Heilongjiang People's Publishing House, June 1989.

[5] He, Tingying. Cultivation of Cultural and Creative Talents from the Perspective of the Cultural Power Strategy [J]. Journal of Shanghai Institute of Economic Management, 2017, 15 (05): 41-47.

[6] $\mathrm{Mu}$ Zhengchen. The development and design of creative derivatives of museum collection resources, [D]. Tianjin University of Technology, 2018.

[7] The cultural and creative products in museums all over the world Beyond Imagination! http://www.sohu.com/a/209714519_207495. 2017-12-11 09:19.

[8] The key to the development of art derivatives is to enhance creativity and quality. 2017-09-24, [A15] Collection Weekly Cover.

[9] Lin Zhuhua. Appreciation of Pottery Figurines in Han Dynasty [J]. Collection. Auction, 2004 (1): 60-61.

[10] Zhao, Fang. "The Artistic Features of Yue Wu Yong in the Han Dynasty" [J]. Jingdezhen Ceramics, 2008 (04): 32-33.

[11] Xi Ran, Blue Coral cultural literacy Ben - Chinese sculpture, Higher Education Press, 2009.

[12] Yang Yongshan. Art Textbook for Grade 5 of Primary School. People's Education Press. 2014.

[13] Art Textbook for Grade 5 of primary school (Korea). 2018.

[14] LiJun. The Study of Exploration and Utilization of Museum Curriculum Resources. 2012.

[15] Lu Yuehong. The Study of the Co-operation in Schools' Art Education and Museums. 2002. 


\section{Biography}

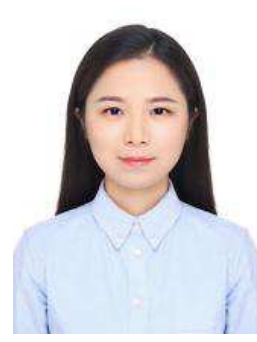

Han Shushu, studying for a Ph.D. degree Major in Cultural Contents at Joongbu University in the Republic of Korea. This essay was written under the guidance of Professor Ho Kang of Joongbu University. At present, she is mainly engaged in art education, and research field is contemporary art painting and art education. 